\title{
Medical Student Research during a Longitudinal Community-Based Placement Can Provide Opportunities for Learning about Public Health
}

\author{
Kathryn Weston *, Judy Mullan, Warren Rich and Peter McLennan (D) \\ School of Medicine, University of Wollongong, Wollongong 2522, Australia; jmullan@uow.edu.au (J.M.); \\ wrich@uow.edu.au (W.R.); petermcl@uow.edu.au (P.M.) \\ * Correspondence: kathw@uow.edu.au \\ Received: 22 November 2017; Accepted: 8 April 2018; Published: 23 April 2018

\begin{abstract}
While 'public health medicine' is a specialised field, most medical practitioners practice 'public health' to some extent, e.g., undertaking preventative screening tests or advising individuals about lifestyle interventions. While requirements to demonstrate capability in public health are common to medical education around the world, medical programs face a challenge to integrate public health education and promote health advocacy in an environment where the doctor: patient relationship is at the core of learning. Students who spend part of their medical education working within general practice or community settings have an opportunity to observe and identify issues of public health importance, and to see how they impact at both a personal and a population level. This paper aims to illustrate how a year-long research project can provide an opportunity for medical students to learn about public health issues and methods to investigate them. Analysis was undertaken of the research topics chosen by eight successive cohorts of medical students, representing 519 students, who successfully completed a research project. Over half of the student research projects $(51.8 \%)$ directly related to Australian national health priority areas of dementia, obesity, arthritis and musculoskeletal conditions, asthma, diabetes, mental health, injury prevention and control, cardiovascular health and cancer control, and a further $28.5 \%$ of projects had a specific public health focus, within domains that include lifestyles and health, communicable disease, and healthy growth and development. Researching public health topics in the community setting represents a practical way to engage medical students in learning about public health, and can help to develop their potential to become 'clinician researchers', investigating and understanding issues relevant to their communities.
\end{abstract}

Keywords: public health; medical education; medical student; research capacity; clerkship; Australia

\section{Introduction}

'Public health medicine' is a specialist medical practice particularly addressing the health and care of populations, including the promotion of health and prevention of disease, illness and injury. It also encompasses the assessment of a community's health needs, and provision of services to communities in general and to specific groups therein [1]. Most medical practitioners, and especially generalists, practice 'public health' to some extent, e.g., undertaking preventative screening tests or advising individuals about lifestyle interventions, such as quitting smoking or improving diet and exercise behaviours. Many also practice public health advocacy, actively working to improve the health of a community or population [2].

Requirements to demonstrate capability in public health are common to medical education around the world. For example, the General Medical Council (GMC) in the United Kingdom has included public health capabilities as part of the attributes of the modern medical graduate [3]. Explicitly, according to the GMC, graduates should be able to "apply to medical practice the principles, method and knowledge 
of population health and the improvement of health and healthcare" [3]. Furthermore, the UK postgraduate training curricula include a requirement for understanding and applying population health principles, including epidemiology, public health, disease prevention, and environmental and social influences on health [4]. In Australia, the general practice training curriculum describes five domains of general practice required for competent unsupervised practice [5]. The third domain is "population health and the context of general practice" and cites examples that include epidemiology, public health, and prevention. The Canadian Family Medicine residency program includes health advocacy in the form of responding to community needs and identifying ways to promote the health of patients and communities [6].

Public health relates to the protection of health of entire populations, including at the relatively small local neighbourhood level, or an entire country or global region [7]. The current medical education literature describes a range of academic programs to integrate 'public health' into medical curricula including through community-based activities, often with a research component $[8,9]$. A focus on population health in a medical student's placement community is logical as the local populace is where 'public health happens'. In an epidemiological sense, each community has specific, and sometimes unique, demographics, as well as particular local and potentially global health issues and distinct healthcare needs: a community with an over-representation of ageing residents may need to prioritise chronic disease management and access to primary care; in contrast, a community severely affected by drought or high unemployment may be in need of increased access to mental health care.

The role of the general practitioner is not restricted to care for the individual patient but extends to responsibility for the wider population $[10,11]$. It is the local environment which is a major determinant of health status [12]. Australian national health priority areas contributing significantly to the burden of disease in Australia include cardiovascular health, mental health and diabetes mellitus [13]. These conditions are frequently encountered in general practice settings, as are health promotion opportunities and screening and prevention strategies [14]. Students who spend part of their medical education within general practice or community settings have an opportunity to observe and identify these issues of public health importance, and their impact at both a personal and a population level. They may also experience opportunities for health advocacy in their communities [2]. While the influence of public health advocacy is well-recognised at national and international levels, exemplified by champions of tobacco control such as Professor Simon Chapman [15], advocacy by individuals at a local level is equally necessary and important. Doctors and medical organisations still have significant influence in community and political spheres [16].

The Ottawa Charter for health promotion describes five key action areas, namely building healthy public policy, creating supportive environments for health, strengthening community action for health, developing personal skills, and re-orienting health services [17]. Effective engagement with local communities is essential for health professionals who wish to develop strategies that measurably improve the health and lives of community members [2]. As doctors-in training, medical students on long-term community placements can directly observe, experience and contribute to public health and health promotion in action. Students are in a position to implement policies and guidelines and administer public health services such as vaccination and screening. Moreover, the combination of community-based clinical experiences and a research or evaluation activity can provide students the opportunity to understand how evidence is generated and used for health improvement [18]. Student investigations can include researching community attitudes to health issues, evaluation of new guidelines or programs, surveillance of health status indicators, and development of interventions based on research findings. These activities reflect the importance of the Ottawa Charter for health promotion, particularly in creating supportive environments for health.

In 2010, the Association of American Medical Colleges and the US Centers for Disease Control convened a conference of medical and public health educators and public health practitioners from the US and Canada. The conference, Patients and populations: Public Health in Medical Education, was an opportunity for focused reflection and consideration on the issue of teaching public health and the need for clearly 
defined principles as medical schools embrace the importance of integrating public health into medical curricula globally [19]. Speakers described the importance of medicine and public health as a continuum and the need for integrated public health and clinical medicine. Importantly, the conference highlighted, and provided insight into, the many challenges associated with integrating public health into medical curricula. These included the low priority of the topic at an institutional level, the perception by students that public health lacks relevance, and the lack of expert faculty staff to teach public health. The conference provided a forum for sharing of innovative curricula models and strategies aimed to integrate public health into medical teaching [19]. Suggestions discussed included integrating public health into existing curricula material rather than developing a new subject; enlisting experienced champion(s) to help develop the content; establish the relevance of public health through experiential learning including community health programs and student-driven research; and realising the value of partnerships with community [20-25]. Other topics included the place of environmental health in the curriculum, and how to incorporate student assessments of public health [26,27].

In light of the above evidence demonstrating the importance attached to graduate attributes of public health knowledge and application, the question then arises: how best can medical educators promote an understanding of public health issues, and public health practice, in a medical education environment where the doctor:patient relationship, at an individual level, is at the core of learning? This paper aims to illustrate how medical student research in a community placement can provide opportunities for students to learn about public health issues and public health practice. Core to student development is a whole class longitudinal integrated community-based clerkship placement and a year-long research project in the placement location.

\section{What Was Done}

\subsection{Public Health Learning Prior to the Longitudinal Community-Based Placement}

Before describing the medical students' year-long research activity, it is important to describe the engagement in public health and research skills earlier in the course. Case-based learning is one of the major educational strategies underpinning the four-year graduate-entry medical program of the University of Wollongong (UOW) [28] and cases are developed around 93 core clinical presentations (e.g., headache, chest pain, lump). Supporting the core presentations are the themes of clinical competencies, medical sciences, research and critical analysis (RCA), and personal and professional development. Educational and scholarly activities frequently incorporate issues of public health importance, including topics such as vaccination, social determinants of health, chronic disease, cardiovascular health, cancer control, population based-screening programs, and smoking cessation. Students thus acquire knowledge, skills and attitudes in a way which could promote the effective application of public health to clinical practice and specific health topics.

Public health knowledge, skills and attitudes come together even further, as part of the Research and Critical Analysis (RCA) theme which supports the students' learning of aspects of epidemiology, evidence-based medicine, critical appraisal, and public health investigative skills [29]. Where possible, specific public health examples are incorporated in case-based learning using examples relevant to the clinical topics being studied, e.g., discussion about the epidemiology of an outbreak of Legionnaires disease during a respiratory disease case. Similarly, within the 'gastro-intestinal' body system block, students learn about population-based screening and the concepts of specificity and sensitivity during large-group sessions and journal club activities relating to population-based screening using faecal-occult blood testing.

\subsection{Research during the Longitudinal Community-Based Placement}

In the students' final years, a capstone research project is a required assessment task and builds on prior learning of the first 2.5 years of the course [29]. This activity is undertaken over a 12-month period in one of ten locations in New South Wales, Australia (Phase 3) [30]. These locations vary 
from large urban centres (non-capital city) through to regional and rural communities [31]. The aim of the student research, supervised by experienced research academic staff [29], is to undertake a project of relevance to the community placement location. The prior learning of public health skills including statistics, critical appraisal of literature and epidemiology underpins the knowledge base required for the research projects.

When undertaking their research, students employ research principles of literature searching, development of a research idea and method, gaining research ethics approval, statistical or descriptive analysis, report writing, and dissemination and communication, including a presentation to peers and academics, and often to community members in the placement location. The outputs required by each student are the research question and project proposal, human research ethics submission and approval, a final journal-style report, and poster and oral presentations. Students are able to self-select their topics for research.

\subsection{Investigation of Abstracts}

We investigated the nature of the research topics undertaken by the students since the inception of the UOW medical program by analysing each student's 250-word abstract submitted with the research report. The abstracts represented 519 individually completed research projects from the first eight cohorts of medical students, who completed Phase 3 between 2010 and 2017. The text was analysed for specific health topic and research method employed. Although the projects sometimes covered more than one health topic, the predominant health issue for each project was identified for this analysis.

These predominant health issues were then mapped against the Australian national health priority areas of dementia, obesity, arthritis and musculoskeletal conditions, asthma, diabetes, mental health, injury prevention and control, cardiovascular health and cancer control [13] The national health priority areas represent a significant contribution to the burden of disease, illness and injury in the Australian community, and a particular cost impost on regional, rural and remote Australia [32]. Addressing medical workforce mal-distribution in rural areas of Australia is a mission of the UOW medical school [33].

The remaining research topics not allocated to the national health priority list were then scrutinized to identify whether they represented other population health issues, such as those that may have impact on quality of life; impact on morbidity and mortality statistics; are preventable or modifiable; have an impact on society; or affect whole groups. These broad groupings of issues fall under the categories of 'public health domains' [34]. The nine public health domains include communicable disease, healthy growth and development, lifestyles and health, and sexual and reproductive health. Research topics that fell under the domains of mental health and wellbeing or substance abuse were included in the earlier mapping against the national priority health area of mental health; and those that fell under the domain of injury prevention were similarly allocated to that respective national priority health area.

\section{Results}

We found that just over half $(51.8 \%)$ of the medical student project topics specifically related to Australian national health priority areas ([13]; Table 1).

Table 1. Australian health priority areas researched by medical students.

\begin{tabular}{ccc}
\hline Health Issue or Topic & N (of 519) & \% \\
\hline Diabetes mellitus & 67 & 12.9 \\
Cardiovascular health & 62 & 11.9 \\
Cancer control & 55 & 10.6 \\
Mental health & 38 & 7.3 \\
Arthritis and musculoskeletal conditions & 24 & 4.6 \\
Injury prevention \& control & 11 & 2.1 \\
Dementia & 7 & 1.3 \\
Asthma & 5 & 1.0 \\
\hline Total & $\mathbf{2 6 9}$ & $\mathbf{5 1 . 8}$ \\
\hline
\end{tabular}


A further $28.5 \%$ of topics also related to specific population health issues under the grouping of public health domains [34] (Table 2). Importantly, within these topics, there were 34 projects $(6.6 \%$ of the total projects) that specifically looked at the issue of access and equity of health care for Australian rural communities.

Table 2. Additional research topics mapped by public health domains.

\begin{tabular}{lc}
\hline \multicolumn{1}{c}{ Public Health Domain } & N (of 519) \\
\hline Lifestyles and Health & \\
Rural access \& equity in healthcare & 34 \\
Lifestyle/exercise & 10 \\
\hline Communicable Disease & \\
Vaccination & 27 \\
Infectious disease & 27 \\
\hline Healthy Growth and Development & \\
Maternal and women's health & 19 \\
Infant/child health & 17 \\
\hline Sexual and Reproductive Health & 11 \\
Sexual health & \\
\hline Environmental Health & 3 \\
Environmental Health & $N=\mathbf{1 4 8}(\mathbf{2 8 . 5 \% )}$ \\
\hline Total &
\end{tabular}

Other topics investigated by $7.2 \%$ of the medical students were medical education in placement communities, doctor workforce issues, and Indigenous health.

Table 3 outlines the research methods employed, which included community-based surveys and interviews of patient knowledge, experiences and attitudes (52.1\%), clinical audits (36.3\%), focus groups, interventions, and literature and systematic reviews.

Table 3. Research methods used in medical student projects.

\begin{tabular}{ccc}
\hline Research Method & N & $\mathbf{\%}$ \\
\hline Survey or interview & 269 & 52.1 \\
Retrospective audit & 115 & 22.3 \\
Audit & 73 & 14.1 \\
Data analysis & 21 & 4.1 \\
Literature/systematic review & 13 & 2.5 \\
Other (focus group, intervention, education) & 25 & 4.8 \\
\hline
\end{tabular}

\section{Discussion}

According to The World Health Organisation, public health is a "social and political concept which aims to improve health, prolong life and improve the quality of life of whole populations through health promotion, disease prevention and other health intervention activities" [35]. Based largely in general practice, the longitudinal clinical placement experience of UOW medical students described here is an opportunity to experience public health first-hand [36]. General practice is the setting for priority public health issues to be observed and managed, including chronic disease care, population health screening and intervention activities, and mental health encounters [37]. Community-based longitudinal clinical placements are thus valued as situated experienced-based learning, including engagement and relationship-building, both formal and informal learning, and extension into the community, enabling our future doctors to be educated to notice and understand links between medical and social issues within their communities and beyond $[38,39]$. 
A Canadian study of medical students' perceptions of public health education revealed that students would prefer a public health curriculum that was more challenging and applied, with field experience and exposure to community-medicine physician role models [40]. The community-based research experiences reported here during long-term clinical placements represent an authentic 'field' experience of public health, including identifying public health issues, investigating the impact of interventions, and developing skills in public health methods. The great majority of the research topics investigated directly related to public health or are national health priority areas in the Australian context. These experiences support Woodward's assertion that practical demonstrations of the application of public health principles to clinical problem solving may be most effective in demonstrating the relevance and importance of public health to medical students [41]. The topics selected by students for research were mapped against two frameworks: the Australian national health priority areas [13] and the National Public Health Partnership's framework for public health practice [34]. The topics could equally have been mapped against the Australian Institute for Health and Welfare's definition of public health, namely activities as those that are focused on "prevention, promotion and protection rather than on treatment, on populations rather than on individuals, and on the factors and behaviours that cause illness and injury rather than the injury itself" [42]. These are classified by AIHW under health and welfare expenditure on public health undertaken or funded by key jurisdictional health departments. Regardless of the framework used, the topics represent learning opportunities for students to better understand both public health issues and methods to investigate them. The $6.6 \%$ of project topics relating to access and equity in providing healthcare in rural areas demonstrates the benefit of being placed in an under-served community for recognising specific health issues faced by such communities.

All student projects incorporated one or more research methods, such as sampling, epidemiology, statistical analysis, research ethics, and other methods of enquiry such as qualitative research and health care evaluation. Thus, the research activity involved not only investigating topics of public health relevance but engagement with, and use of, a range of public health methods and approaches. Undertaking community-based research can provide students with the opportunity to develop skills as 'clinician researchers'. The community-based, population health focus of research during medical education challenges the common perception of a clinician scientist being the laboratory-based specialist, seeking large funding grants and space for benchtop research [43]. Generalist practitioners in any setting can be researchers $[44,45]$. Seeking to identify and understand issues of public health relevance in a community setting is a critical form of research. Moreover a research-aware practitioner can promote early translation of research findings into clinical practice or can engage with other researchers to investigate an issue that has become apparent through observation. It is well recognised that early exposure to research is an important element in the development of clinicians who are research-aware and research-active [46]. Moreover, understanding the importance of ethical conduct of research can develop good practice amongst early-career researchers [47,48]. Thus, all UOW students are required to submit a human research ethics application before undertaking their community-based research and are mentored by experienced academics.

The Ottawa Charter for health promotion describes key actions that include creating supportive environments for health, and enabling, medicating and advocating [17]. The research approach of over half of the medical student projects involved engagement with the students' communities through surveys and focus groups, and some of the student findings have been incorporated into locally relevant interventions, such as fact sheets. Medical student research within the medical education curriculum can thus work towards enabling health improvements as per the Ottawa Charter.

Published research has already shown statistically significant improvement in UOW medical students' research capability over the course of their longitudinal research experience [29]. Some medical students have already disseminated their findings as peer-reviewed journal publications and conference presentations [29], and their undertakings also allow improved research opportunities and increased research capacity of the regional and rural practitioners, hospital and medical practice staff supervising 
the students and engaged in local research as scholars and collaborators [49,50]. Further, the process has spawned opportunities for recent UOW medical graduates to mentor current students. One recent graduate of the program has initiated research during internship and is currently providing opportunities for two medical students to collaborate on the project, as part of their student research projects.

Developing interests and skills in public health may enable medical graduates to advocate for public health across a wide sphere. For instance, global recognition of the link between the environment and health provides an opportunity for doctors to contribute their research and communication skills to the preparation of submissions about urban planning and housing development applications in their communities, for example, promoting the need for safe walkable streets, green space, good quality air and activities suitable for all ages and mobility [51]. The cultural authority of doctors is respected and recognised, so they are well placed to advocate for waste reduction and lessen the environmental impact of hospital and healthcare centres [52]. Health advocacy could include negotiation with fast food industries regarding healthy food options, or working with business to help the unemployed access industry experience. Helping to secure employment opportunities could help to mitigate against mental health issues in the long-term unemployed [53].

Fineberg (2011) described six ways that public health education and medical care are linked: through the science of epidemiology, including understanding of and application of medical literature; through the influence of environmental, social, psychological and other factors on health; through appreciation of the role and impact of public health interventions; understanding cultural sensitivities; employing systems thinking; and the broad array of career and experiential opportunities for medical graduates to engage in issues of public health [54]. The results presented here clearly reveal it is possible for medical students to engage in public or population health research in the community as part of their medical education. Establishing relevance through experiential learning demonstrates to students the meaningful intersection between medical education theory and teaching of public health and the principles of public health practice.

The contemporary public health challenges of global disparities in health, medication safety, climate change, obesity and diabetes epidemics, an ageing population, and returning and emerging infections are on our doorstep, and our doctors and other health professionals need to be able to recognise these issues and respond to individual and community needs, and importantly, they need to have skills and confidence to be advocates in areas of policy and public health funding. Ness (2011) suggests that the solutions to these crises require significant innovation [55]. The first steps in this process are education during training and provision of opportunities for students to learn by experience. Thus, medical education should reflect the values of the Ottawa charter for health promotion, and the importance of developing health promotion skills of junior doctors.

It is essential to look to the future to ensure our graduating doctors and other health professionals are capable of meeting public health challenges as they arise. In addition to innovation as Ness advocates [55], educators should celebrate and support alternative ways for health professional graduates to be advocates for public health. The program described above to engage students in authentic and relevant research is applicable across all health professional education [35]. It can also support other novel approaches to research: doctors and other health professionals can engage with their community, not only in benchtop or community-based research, but also in citizen science activities, fast becoming a popular community occupation with potential to increase engagement with, and acceptance of, science across the demographic spectrum [56]. Improved technology allows public health advocacy to be more adventurous and to have wider acceptance, for example by using photo voice, or digital storytelling, or developing aspects of medical humanities as a vehicle for public health awareness [57,58]. Beyond their communities, graduates can link into news and advice alerts such as from the World Health Organisation and be influential in advocating for improvements at a global level. 


\section{Conclusions}

While much of the core of medical education reflects the doctor:patient individual care model, there is a place for involving students in public health practice during training. Undertaking a community-based research project during a longitudinal clerkship placement allows students to see the impact of health issues at a population level, build confidence and capacity in engaging with community members, develop skills as clinician researchers, and realise their potential to make a difference to their communities and beyond.

Author Contributions: K.W., J.M. and P.M. conceived and designed the data collection and analysis; K.W. analyzed the numerical data and wrote the first draft of the paper; W.R. provided support for the data collection and analysis; all authors contributed to the final manuscript.

Conflicts of Interest: The authors declare no conflicts of interest.

\section{References}

1. Public Health Medicine Advanced Training Curriculum. Australasian Faculty of Public Health Medicine. The Royal Australasian College of Physicians, 2013. Available online: https:/ / www.racp.edu.au/docs/defaultsource/default-document-library/at-afphm-public-health-medicine-advanced-training-curriculum.pdf? sfvrsn=2 (accessed on 21 June 2017).

2. Bassett, M.T. Public health advocacy. Am. J. Public Health 2003, 93, 1204. [CrossRef]

3. Tomorrow's Doctors. Outcomes and Standards for Undergraduate Medical Education; General Medical Council: Manchester, UK, 2009; Available online: http:/ / www.gmc-uk.org/Tomorrow_s_Doctors_1214.pdf_48905759.pdf (accessed on 21 June 2017).

4. Domain 4: Capabilities in health promotion and illness prevention. In Postgraduate Education and Training; General Medical Council: Manchester, UK; Available online: http://www.gmc-uk.org/education/ postgraduate/30979.asp (accessed on 21 June 2017).

5. The Five Domains of General Practice. Curriculum for Australian General Practice 2016. Royal Australian College of General Practitioners. Available online: https:/ / www.racgp.org.au/Education/Curriculum/Thefive-domains-of-general-practice (accessed on 4 April 2018).

6. Shaw, E.; Oandasan, I.; Fowler, N. (Eds.) CanMEDS-FM 2017: A Competency Framework for Family Physicians across the Continuum; The College of Family Physicians of Canada: Mississauga, ON, Canada, 2017.

7. What Is Public Health? CDC Foundation. Available online: https:/ /www.cdcfoundation.org/what-public-health (accessed on 4 October 2017).

8. Grochowski, C.O.C.; Halperin, E.; Buckley, E. A curricular model for the training of physician scientists: The evolution of the Duke University School of Medicine curriculum. Acad. Med. 2007, 82, 375-382. [CrossRef] [PubMed]

9. Rosenthal, M.S.; Lucas, G.I.; Tinney, B.; Mangione, C.; Schuster, M.A.; Wells, K.; Wong, M.; Schwarz, D.; Tuton, L.W.; Howell, J.D.; et al. Teaching community-based participatory research principles to physicians enrolled in a health services research fellowship. Acad. Med. 2009, 84, 478-484. [CrossRef] [PubMed]

10. Population Health and Public Health. The RACGP Curriculum for Australian General Practice 2016. Available online: http:/ / curriculum.racgp.org.au/statements/population-health-and-public-health/ (accessed on 22 November 2017).

11. Porter, G.; Blachki, G.; Grills, N. General practice and public health: Who is my patient? Aust. Fam. Phys. 2014, 43, 483-486.

12. The Determinants of Health. Health Impact Assessment (HIA). World Health Organization, 2018. Available online: http:/ / www.who.int/hia/evidence/doh/en/ (accessed on 8 April 2018).

13. National Health Priority Areas. Australian Institute of Health and Welfare 2017, Australian Government, Canberra. Available online: http:/ / www.aihw.gov.au/national-health-priority-areas / (accessed on 12 June 2017).

14. Cooke, G.; Valenti, L.; Glasziou, P.; Britt, H. Common general practice presentations and publication frequency. Aust. Fam. Phys. 2013, 42, 65-68.

15. Chapman, S. Reflections on a 38-year career in public health advocacy: 10 Pieces of advice to early career researchers and advocates. Public Health Res. Pract. 2015, 25, e2521514. [CrossRef] [PubMed]

16. Kmietovicz, Z. R.E.S.P.E.C.T.-Why doctors are still getting enough of it. Br. Med. J. 2002, 324, 11. [CrossRef] 
17. The Ottawa Charter for Health Promotion. Health Promotion. In Proceedings of the First International Conference on Health Promotion, Ottawa, Canada, 21 November 1986; World Health Organization: Geneva, Switzerland, 2018; Available online: http:/ / www.who.int/healthpromotion/conferences/previous/ottawa/ en/index4.html (accessed on 8 April 2018).

18. Brownson, R.C.; Fielding, J.J.; Mavlahn, C.M. Evidence-based public health: A fundamental concept for public health practice. Ann. Rev. Public Health 2009, 30, 175-201. [CrossRef] [PubMed]

19. Maeshiro, R.; Koo, D.; Keck, C.W. Integration of public health into medical education: An introduction to the supplement. Am. J. Prev. Med. 2011, 41, S145-148. [CrossRef] [PubMed]

20. Johnson, I.L.; Scott, F.E.; Byrne, N.P.; MacRury, K.A.; Rosenfield, J. Integration of Community Health Teaching in the Undergraduate Medicine Curriculum at the University of Toronto. Am. J. Prev. Med. 2011, 41, S176-S180. [CrossRef] [PubMed]

21. Carney, J.K.; Maltby, H.J.; Mackin, K.A.; Maksym, M.E. Community-Academic Partnerships: How Can Communities Benefit? Am. J. Prev. Med. 2011, 41, S206-S213. [CrossRef] [PubMed]

22. McNeal, M.S.; Blumenthal, D.S. Innovative Ways of Integrating Public Health into the Medical School Curriculum. Am. J. Prev. Med. 2011, 41, S309-S311. [CrossRef] [PubMed]

23. Betz, M.E.; Bernstein, S.L.; Gutman, D.C.; Tibbles, C.D.; Joyce, N.R.; Lipton, R.I.; Schweigler, L.M.; Fisher, J. Public Health Education for Emergency Medicine Residents. Am. J. Prev. Med. 2011, 41, S242-S250. [CrossRef] [PubMed]

24. Carney, J.K.; Schilling, L.M.; Frank, S.H.; Biddinger, P.D.; Bertsch, T.F.; Grace, C.J.; Finkelstein, J.A. Planning and Incorporating Public Health Preparedness into the Medical Curriculum. Am. J. Prev. Med. 2011, 41, S193-S199. [CrossRef] [PubMed]

25. Mahoney, J.F.; Fox, M.D.; Chheda, S.G. Overcoming challenges to integrating public health and population health into medical curricula. Am. J. Prev. Med. 2011, 41, S170-S175. [CrossRef] [PubMed]

26. Gehle, K.S.; Crawford, J.L.; Hatcher, M.T. Integrating Environmental Health into Medical Education. Am. J. Prev. Med. 2011, 41, S296-S301. [CrossRef] [PubMed]

27. Novick, L.F.; Lazorick, S.; Clay, M.C.; Merricks, P.A.; Daugherty, J.C.; Efird, J.T. Using Clinical Skills Exams to Evaluate Medical Student Skills in Prevention. Am. J. Prev. Med. 2011, 41, S181-S186. [CrossRef] [PubMed]

28. Mansfield, K.J.; Sanzone, S.; Parker-Newlyn, L.A.; Bushnell, J.A. Case based learning with live patients-Engaging students and community for effective learning. In Proceedings of the Higher Education Research and Development Society of Australasia Inc. Conference, Hobart, Australia, 2-5 July 2012.

29. Mullan, J.R.; Weston, K.M.; Rich, W.C.; McLennan, P.L. Investigating the impact of a research-based integrated curriculum on self-perceived research capabilities of medical students in rural and regional placements: A preand post-test analysis of three student cohorts. BMC Med. Ed. 2014, 14, 161. [CrossRef]

30. Hudson, J.N.; Weston, K.M.; Farmer, E.A. Engaging rural preceptors in new longitudinal community clerkships during workforce shortage: A qualitative study. BMC Fam. Prac. 2011, 12, 103. [CrossRef] [PubMed]

31. Weston, K.M.; Garne, D.L.; Bushnell, J.A.; Hudson, J.N. The big city by-pass: Origin is important in medical students' preference for future practice in regional cities and large towns. Focus Health Prof. Educ. Multi-Prof. J. 2018, 19, 12-24. [CrossRef]

32. National Health Priority Areas. Garvan Institute of Medical Research. Garvan Institute, 2018. Available online: https:/ / www.garvan.org.au/our-work/rural-health/priority-areas (accessed on 8 April 2018).

33. Hudson, J.N.; Farmer, E.A.; Weston, K.M.; Bushnell, J.A. Using a framework to implement large-scale innovation in medical education with the intent of achieving sustainability. BMC Med. Educ. 2015, 15, 2. [CrossRef] [PubMed]

34. A Planning Framework for Public Health Practice. National Public Health Partnership, September 2000. Available online: http:/ / www.health.nsw.gov.au/research/Documents/planning-framework.pdf (accessed on 8 April 2018).

35. Health Promotion Glossary; World Health Organization: Geneva, Switzerland, 1998; Available online: http:/ / www. who.int/healthpromotion/about/HPR\%20Glossary\%201998.pdf (accessed on 8 April 2018).

36. Weston, K.; Mullan, J.; McLennan, P.; Rich, W. Community-based research projects within a medical curriculum: Authentic learning of public health. In Proceedings of the Public Health Association of Australia 42nd Annual Conference, Melbourne, Australia, 16-18 September 2013.

37. Harris, M. The interface between primary health care and population health: Challenges and opportunities for prevention. Public Health Res. Pract. 2016, 26, e2611601. [CrossRef] [PubMed] 
38. Dornan, T.; Scherpbier, A.; Boshuizen, H. Supporting medical students' workplace learning: Experience-based learning (ExBL). Clin. Teach. 2009, 6, 167-171. [CrossRef]

39. Poncelet, A.N.; Mazotti, L.A.; Blumberg, B.; Wamsley, M.A.; Grennan, T.; Shore, W.B. Creating a Longitudinal Integrated Clerkship with Mutual Benefits for an Academic Medical Center and a Community Health System. Perm. J. 2014, 18, 50-56. [CrossRef] [PubMed]

40. Tyler, I.V.; Hau, M.; Buxton, J.A.; Elliott, L.J.; Harvey, B.J.; Hockin, J.C.; Mowat, D.L. Canadian medical students' perceptions of public health education in the undergraduate medical curriculum. Med. Ed. 2009, 84, 1307-1312. [CrossRef] [PubMed]

41. Woodward, A. For debate: Public Health has no place in undergraduate medical education. J. Public Health Med. 1994, 16, 389-392. [CrossRef] [PubMed]

42. Australian Institute of Health and Welfare. Public Health Expenditure in Australia 2008-09. In Health and Welfare Expenditure Series No. 43. Cat. No. HWE52; AIHW: Canberra, Australia, 2011.

43. Kennedy, P.G.E. My Life as a Clinician-Scientist: Trying to Bridge the Perceived Gap between Medicine and Science. DNA Cell Biol. 2015, 34, 383-390. [CrossRef] [PubMed]

44. Ried, K.; Fuller, J. Building a culture of research dissemination in primary health care: The South Australian experience of supporting the novice researcher. Aust. Health Rev. 2005, 29, 6-11. [CrossRef] [PubMed]

45. Wilson, P. Defending the GP clinician-researcher. Br. J. Gen. Pract. 2009, 59, 212. [CrossRef] [PubMed]

46. O'Sullivan, P.A.; Niehaus, B.; Lockspeiser, T.M.; Irby, D.M. Becoming an academic doctor: Perceptions of scholarly careers. Med. Educ. 2009, 43, 335-341. [CrossRef] [PubMed]

47. Costello Ingham, J. Research Ethics 101: The Responsible Conduct of Research. Semin. Speech Lang. 2003, 24, 323-338.

48. Willison, D.J.; Ondrusek, N.; Dawson, A.; Emerson, C.; Ferris, L.E.; Saginur, R.; Sampson, H.; Upshur, R. What makes public health studies ethical? Dissolving the boundary between research and practice. BMC Med. Ethics 2014, 15, 61. [CrossRef] [PubMed]

49. Weston, K.M.; Hudson, J.N. Clinical scholarship amongst preceptors supervising longitudinal integrated medical clerkships in regional and rural communities of practice. Aust. J. Rural Health 2014, 22, 80-85. [CrossRef] [PubMed]

50. Weston, K.M.; Mullan, J.R.; Rich, W.C.; Crowther, S.; Bushnell, J.A.; McLennan, P.L. Graduating work-ready professionals: Research competency as a critical curriculum component. Curric. Teach. 2017, 32, $25-44$. [CrossRef]

51. Northridge, M.E.; Sclar, E.D.; Biswas, P. Sorting out the connections between the built environment and health: A conceptual framework for navigating pathways and planning healthy cities. J. Urban Health 2003, 80, 556-568. [CrossRef] [PubMed]

52. Eckelman, M.J.; Jodi Sherman, J. Environmental Impacts of the U.S. Health Care System and Effects on Public Health. PLoS ONE 2016, 11, e0157014. [CrossRef] [PubMed]

53. Watson, B.; Osberg, L. Healing and/or breaking? The mental health implications of repeated economic insecurity. Soc. Sci. Med. 2017, 188, 119-127. [CrossRef] [PubMed]

54. Fineberg, H.V. Public Health and Medicine Where the Twain Shall Meet. Am. J. Prev. Med. 2011, 41, S149-S151. [CrossRef] [PubMed]

55. Ness, R.B. Public Health Research Priorities for the Future. Public Health Rev. 2011, 33, 225-239. [CrossRef]

56. Loiselle, S.A.; Frost, P.C.; Turak, E.; Thornhill, I. Citizen scientists supporting environmental research priorities. Sci. Total Environ. 2017, 598, 937. [CrossRef] [PubMed]

57. Saffran, L. 'Only connect': The case for public health humanities. Med. Hum. 2014, 40, 105-110. [CrossRef] [PubMed]

58. Saffran, L. Emotional Life: Exploring Contradictions in Health Behavior through Creative Writing in Public Health Education. Acad. Med. 2017, 92, 1234-1235. [CrossRef] [PubMed]

(C) 2018 by the authors. Licensee MDPI, Basel, Switzerland. This article is an open access article distributed under the terms and conditions of the Creative Commons Attribution (CC BY) license (http://creativecommons.org/licenses/by/4.0/). 